\title{
Descriptive study of the role of household type and household composition on women's reproductive health outcomes in urban Uttar Pradesh, India
}

llene S Speizer ${ }^{1,2^{*}}$, Peter Lance ${ }^{2}$, Ravi Verma ${ }^{3}$ and Aimee Benson ${ }^{2}$

\begin{abstract}
Background: More needs to be known about the role intra-familial power dynamics play in women's reproductive health outcomes, particularly in societies like Northern India characterized by patriarchy and extended families. The key research question we explore is: how important are living arrangements (e.g., presence of the mother-in-law, presence of an elder sister-in-law, and living in the husband's natal home) on contraceptive use behaviors and decision to deliver at an institution?
\end{abstract}

Methods: Representative data collected in 2010 from six cities in Uttar Pradesh are used to examine the above research question. This study uses multivariable logistic regression methods to examine the association between women's household type (husband's natal home vs. not husband's natal home) and household composition (lives with mother-in-law; and lives with elder sister-in-law) and modern family planning use and institutional delivery.

Results: More than sixty percent of women in the sample live in their husband's natal home, one-third live with their mother-in-law, and only three percent live with an elder sister-in-law. Findings demonstrate that women who live either with the mother-in-law or in the husband's natal home are more likely to use modern family planning than those women living neither with the mother-in-law nor in the husband's natal home. In addition, living with an elder sister-in-law is associated with less family planning use. For institutional delivery, women who live with the mother-in-law have higher institutional delivery than those not living with the mother-in-law. Multivariable analyses demonstrate that, controlling for other factors associated with modern family planning use, women living with neither the mother-in-law nor in the husband's natal home are the least likely to use modern family planning. Similar findings are found for institutional delivery such that those women living with neither the mother-in-law nor in the husband's natal home are the least likely to have an institutional delivery, controlling for demographic factors associated with institutional delivery.

Conclusions: Where women live and who they live with matters. Future reproductive health programs for urban India should consider these context specific factors in programs seeking to improve women's reproductive health outcomes.

Keywords: Family planning, Institutional delivery, Household type, Mother-in-law, Urban, India

\footnotetext{
* Correspondence: speizer@email.unc.edu

'Department of Maternal and Child Health, Gillings School of Global Public

Health, The University of North Carolina at Chapel Hill, Chapel Hill, NC, USA

${ }^{2}$ Carolina Population Center, University of North Carolina at Chapel Hill,

Chapel Hill, USA

Full list of author information is available at the end of the article
}

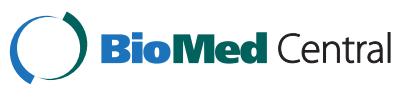

(C) 2015 Speizer et al.; licensee BioMed Central. This is an Open Access article distributed under the terms of the Creative Commons Attribution License (http://creativecommons.org/licenses/by/4.0), which permits unrestricted use, distribution, and reproduction in any medium, provided the original work is properly credited. The Creative Commons Public Domain Dedication waiver (http://creativecommons.org/publicdomain/zero/1.0/) applies to the data made available in this article, unless otherwise stated. 


\section{Introduction}

A key to attaining the Millennium Development Goals (MDG) generally and to reducing maternal mortality by $75 \%$ by 2015 (MDG 5) is achieving universal access to family planning (FP) and reproductive health services [1]. Gaps in attaining universal access to reproductive health and FP are most apparent among the least educated and poorest segments of the population [2-5]. Across multiple countries and in both urban and rural settings, young, poorer, and uneducated women are less likely to use modern FP and to have an institutional delivery [3-5]. These gaps in FP use and institutional delivery may be related to social barriers in contexts where mothers-in-law play an important role in household decision-making [6-8].

To date, numerous studies have been undertaken to understand barriers to modern FP use and institutional delivery globally [9-14] and in India, the site of this study [15-17]. Many of these studies examine the association between education, wealth, and decision-making autonomy and reproductive health outcomes [2,16-20]. These studies often ignore the role of mothers-in-law and others in the household in shaping FP use and institutional delivery [17,21-23]. Family influences are important in South Asia and particularly in Northern India, where women often move into their husband's home after marriage, mother's-in-law are influential in household decision-making, and FP use and institutional delivery levels are lower than neighboring areas [24-27].

Most studies to date regarding the role of living with the mother-in-law in shaping reproductive health outcomes have focused on rural areas, used qualitative data, or used nationally representative surveys $[6,8,12,22-24,28]$. A few exceptions are studies from urban areas in Pakistan using quantitative data that have shown that mothers-in-law remain influential, even in urban settings where women may be more empowered and mobile $[7,29,30]$.

This study contributes to prior research on the role of the mother-in-law in shaping reproductive decisionmaking by including an additional dimension to the study. In particular, we examine the association between household type (i.e., living in the husband's natal home or not) in combination with living with the mother-inlaw and modern family planning use and institutional delivery in urban Uttar Pradesh. We hypothesize that women who live in the husband's natal home with the mother-in-law present will have the most barriers to or influences on their reproductive health outcomes as compared to women who live in their husband's natal home without the mother-in-law or women who live neither with the mother-in-law nor in the husband's natal home. The key research question we explore is: how important are living arrangements (e.g., presence of the mother-in-law and an elder sister-in-law and living in the husband's natal home) on contraceptive use behaviors and the decision to deliver at an institution?

\section{Methods}

The data for this study were collected between JanuaryAugust, 2010 in six cities in Uttar Pradesh India (Agra, Aligarh, Allahabad, Gorakhpur, Moradabad, and Varanasi). The data were collected as baseline data for the evaluation of the Urban Health Initiative, the India-based component of the Bill \& Melinda Gates Foundation funded Urban Reproductive Health Initiative. At baseline, a representative sample of currently married women ages 15-49 was surveyed from each city. The goal was to survey about 3,000 women per city to permit a comprehensive evaluation of the programs at the city level. A total of 17,643 women were interviewed at baseline in the six cities. (See reference [16] for details of the sampling frame and study design.) Eligible households and women were approached by a female interviewer and asked to provide consent to be interviewed. Following consent, the interviewer administered a paper and pencil survey with the respondent. This project was approved by the Futures Group India Institutional Review Board (in-country approval) as well as by the Institutional Review Boards at The University of North Carolina at Chapel Hill and the International Center for Research on Women (ICRW).

For this analysis, the focus is on two outcomes: current use of modern FP and whether the last birth in the last three years was delivered in a health institution. These outcomes were chosen as they represent important reproductive health events that were measured in the baseline survey. For the analysis of modern FP use, women who were fecund and non-pregnant at the time of the study were included. Overall, 3,122 women who were pregnant or infecund were dropped. The analysis sample for the examination of modern family planning use is 14,521 unweighted (14,633 weighted). These women were asked whether they or their husband were currently using a method of family planning and among those who reported using a method, they were asked which method they were using. Responses from these two questions were coded into two groups: users of a modern method (e.g., female and male sterilization, condoms, intrauterine device, injections, oral contraceptive pills, emergency contraceptives, and dermal patch); and non-users or users of a traditional method.

For the analysis of institutional delivery, only women who had a birth in the last three years were included. The analysis sample for institutional delivery has an unweighted sample size of 5,611 and a weighted sample size of 5,427 . These women were asked where they delivered their most recent birth. All women are coded as a) delivered in a health facility (public or private; hospital 
or clinic), or b) delivered at home or in the home of another person (e.g., natal home, relative's home, etc.).

The key independent variables for this analysis relate to the household type and the household composition. In particular, information reported by the woman on location of residence is used to classify if the woman reports that she currently lives in her husband's natal home or not. The two household composition variables of interest were: living with the mother-in-law and living with an elder sister-in-law. The household composition variables were created based on the household survey that included an inventory of all household members and each household member's relationship to the head of the household. Age was also included permitting a determination if the sister-in-law was elder to the index woman. To address the fact that there is an overlap between living with the mother-in-law and in the husband's natal home, for this analysis, we created a joint variable. This variable has four categories: lives in the husband's natal home and with the mother-in-law; lives in husband's natal home only, lives with mother-in-law only; and lives elsewhere (no mother-in-law; not husband's natal home).

The analyses control for factors previously found to be associated with modern family planning use and institutional delivery in this setting $[16,23,31]$. The control variables include: age, education, wealth group, residential site (slum/non-slum), city of residence, caste, and religion. Wealth group was calculated based on reported household assets and environmental circumstances using principal components analysis methods as is done in many large demographic surveys and previously with these data [16]. The woman's number of children born (parity) is also included in the model of institutional delivery as women having a first birth are more likely to deliver in a facility than all other women [32]. See Table 1 for the distribution of the control variables in the two analysis samples.

All univariate and bivariate results presented are weighted; bivariate results are presented using F-tests to demonstrate significance. To examine the association of household type and household composition, we undertake multivariable logistic regression analyses. All multivariable analyses use the unweighted sample and control for the clustered study design by adjusting the standard errors using robust estimator commands in Stata statistical software.

\section{Results}

In Table 1, descriptive characteristics of the study samples are presented. The sample for the family planning use analysis includes a large proportion of women who are age 30 or older. Conversely, for the recent birth sample, the majority of the women are under age 30. In both samples, about a third of the women have no education and another third have 12 or more years of education. In the weighted samples, nearly one-fifth of the sample is from slum areas. At the bottom of Table 1, we present the household type and composition variables for the two analysis samples. Nearly two-thirds of women live in their husband's natal home (adding together the first two categories). One-third of the sample lives with the mother-in-law. Only about three percent of the women live with an elder sister-in-law in the household. Notably, in the family planning analysis sample more than half of women living in the husband's natal home do not have a mother-in-law present: this may be correlated with older age whereby as the woman ages, her motherin-law may no longer be alive. Conversely, in the recent birth sample, more than half of women living in the husband's natal home also live with the mother-in-law. Finally, in both samples, about one third of women live neither with the mother-in-law nor in the husband's natal home.

Not shown in Table 1 is the proportion of the population that lives in their husband's natal home by slum residence. In both analysis samples, seventy-two percent of women who live in slums report living in their husband's natal home whereas about 60 percent of women in the non-slum sites live in their husband's natal home; this difference is significant. There was no difference in living with the mother-in-law or with an elder sister-inlaw between slum and non-slum residents (not shown).

Table 2 provides the bivariate distribution of modern family planning use by the household type and composition variables in the weighted sample. Overall in this sample, 54 percent of women reported using a modern method of FP. Among women who live with their elder sister-in-law, 42 percent report currently using a modern FP method. The percentage using modern FP among women not living with an elder sister-in-law is significantly higher at 54 percent. Among women living only with their mother-in-law and women only living in the husband's natal home, the use of modern family planning is the highest at 58-59 percent. Conversely, women living with both the mother-in-law and in the husband's natal home are the least likely to use ( 49 percent) and those living with neither are also less likely to use (53 percent). Also shown in Table 2 are the percentages of women using contraception in each of the household type/composition categories among women living in slums and women living in non-slum areas. The patterns of use are similar for the slum and non-slum areas for family planning use. These descriptive findings are suggestive of important roles for sisters-in-law and household type/composition. However, these findings may be misleading if women who live both in their husband's natal home and with their mother-in-law (or sister-in- 
Table 1 Descriptive characteristics of currently married women by study sample, Uttar Pradesh, India

Characteristics

Age
$<25$
$25-29$
$30-34$
$35-49$

Education

$$
\begin{aligned}
& \text { None } \\
& \text { 1-7 years education } \\
& \text { 8-11 years education } \\
& 12+\text { years education }
\end{aligned}
$$

\section{Wealth group}

Poorest

Poor

Middle

Rich

Richest

Residential site

$$
\text { Slum }
$$

Parity

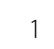

$$
2
$$$$
3
$$$$
4+
$$

City

Agra
Aligarh
Allahabad
Gorakhpur
Moradabad
Varanasi

\section{Caste}

Scheduled caste or tribe

Other backward caste

None

\section{Religion}

Hindi

Muslim/other

Fecund, non-pregnant women in FP sample Women who had a birth in last 3 years (institutional delivery)

$\begin{array}{ccccc}\text { Percentage } & \text { Weighted N } & & \text { Percentage } & \text { Weighted N } \\ 16.9 & 2467 & & 33.8 & 1832 \\ 22.2 & 3253 & & 37.8 & 2049 \\ 22.2 & 3255 & & 20.2 & 1097 \\ 38.7 & 5659 & & 8.3 & 448\end{array}$

30.8

12.4

22.1

34.7

21.2

20.4

20.5

19.4

18.5

18.2

81.8

24.3

27.3

19.9

28.5

24.1

11.6

19.2

15.4

9.2

20.5

18.4

42.6

39.1

96.3

3.7
4511

1815

3235

5073

3104

2980

2994

2839

2716

2666

11967

3549

3997

2910

4117

3520

1701

2812

2258

1339

3003

2686

6228

5719

14096

537
33.4

12.7

21.3

32.7

23.1

20.4

19.2

19.4

17.8

19.6

80.4

31.2

28.8

16.3

23.7

26.6

13.8

17.9

14.1

9.1

18.6

20.3

46.6

33.1

96.8

3.2
1811

688

1155

1772

1256

1108

1041

1054

969

1063

4364

1693

1565

886

1284

1442

748

969

763

494

1011

1103

2529

1796

5252

176 
Table 1 Descriptive characteristics of currently married women by study sample, Uttar Pradesh, India (Continued)

\begin{tabular}{|c|c|c|c|c|}
\hline \multicolumn{5}{|l|}{ Household type and presence of mother-in-law } \\
\hline Lives in husband's natal home with mother-in-law & 27.9 & 4089 & 36.1 & 1960 \\
\hline Lives in husband's natal home only & 34.6 & 5056 & 29.1 & 1580 \\
\hline Lives with mother-in-law only & 3.9 & 497 & 3.0 & 163 \\
\hline Not natal home and no mother-in-law & 34.1 & 4992 & 31.8 & 1724 \\
\hline Presence of elder sister-in-law & 2.8 & 408 & 3.5 & 192 \\
\hline
\end{tabular}

Table 2 Use of modern contraception among currently married, fecund, non-pregnant women from Uttar Pradesh, India ( $n=14,633$, weighted)

\begin{tabular}{|c|c|c|}
\hline Characteristics & $\begin{array}{l}\text { Using modern } \\
\text { method* } \%^{*}\end{array}$ & $\begin{array}{c}\text { Significance } \\
\text { (F-Statistic p-value) }\end{array}$ \\
\hline All women & 53.8 & \\
\hline Presence of elder sister-in-law & & 0.000 \\
\hline No & 54.1 & \\
\hline Yes & 42.0 & \\
\hline $\begin{array}{l}\text { Household type and presence } \\
\text { of mother-in-law }\end{array}$ & & 0.000 \\
\hline $\begin{array}{l}\text { Lives in husband's natal home } \\
\text { with mother-in-law }\end{array}$ & 49.1 & \\
\hline $\begin{array}{l}\text { Lives in husband's natal home } \\
\text { only }\end{array}$ & 58.3 & \\
\hline Lives with mother-in-law only & 58.8 & \\
\hline $\begin{array}{l}\text { Not natal home and no } \\
\text { mother-in-law }\end{array}$ & 52.6 & \\
\hline \multicolumn{3}{|l|}{ Slum sample: } \\
\hline $\begin{array}{l}\text { Household type and presence } \\
\text { of mother-in-law }\end{array}$ & & 0.000 \\
\hline $\begin{array}{l}\text { Lives in husband's natal home } \\
\text { with mother-in-law }\end{array}$ & 45.4 & \\
\hline $\begin{array}{l}\text { Lives in husband's natal home } \\
\text { only }\end{array}$ & 55.2 & \\
\hline Lives with mother-in-law only & 55.5 & \\
\hline $\begin{array}{l}\text { Not natal home and no } \\
\text { mother-in-law }\end{array}$ & 49.3 & \\
\hline \multicolumn{3}{|l|}{ Non-slum sample: } \\
\hline $\begin{array}{l}\text { Household type and presence } \\
\text { of mother-in-law }\end{array}$ & & 0.000 \\
\hline $\begin{array}{l}\text { Lives in husband's natal home } \\
\text { with mother-in-law }\end{array}$ & 49.9 & \\
\hline $\begin{array}{l}\text { Lives in husband's natal home } \\
\text { only }\end{array}$ & 59.2 & \\
\hline Lives with mother-in-law only & 59.2 & \\
\hline $\begin{array}{l}\text { Not natal home and no } \\
\text { mother-in-law }\end{array}$ & 53.1 & \\
\hline
\end{tabular}

*Modern methods include: female and male sterilization, condoms, intrauterine device, injections, oral contraceptive pills, emergency contraceptives, and dermal patch. law) are also younger, less educated, or poorer since these are all factors associated with non-use of modern FP. Multivariable analyses are needed to examine the association between household type and composition on modern FP use controlling for these key demographic factors.

Table 3 presents the bivariate association between household type and composition and institutional delivery. Overall, about 69 percent of women in these urban sites report delivering their last birth in a health institution. Significant differences are observed by household type and composition, although not necessarily in the hypothesized direction. In particular, women who live with their elder sister-in-law, and women who live with the mother-in-law (in the husband's natal home or not in the husband's natal home) are all significantly more likely to have an institutional delivery than their counterparts not living in these settings. At the bottom of Table 3 we present the household type/composition and facility delivery for women living in slum and women in non-slum areas. Across all household type/composition categories, women living in slums are less likely to deliver in an institution. In both slums and non-slums, women living in the husband's natal home and with the mother-in-law are the most likely to deliver in an institution. The slum women who live with the mother-inlaw were the least likely to deliver in a facility (only about 50\%) whereas there is little difference between the other two categories. Among women in non-slum areas, a greater percentage of women living with the motherin-law only reported institutional delivery compared to the two other categories. To better understand the role of household type and composition, we need to control for key demographics that are related to institutional delivery and may also be related to living arrangement, such as having a first birth. Younger couples having their first births may be more likely to live with family and first births are more likely to be delivered in a health institution.

Table 4 presents multivariable logistic regression odds ratios and 95\% confidence intervals for the analysis of factors associated with modern FP use (Model 1) and institutional delivery (Model 2). Of particular interest are the variables at the bottom of the table. Model 1 
Table 3 Institutional delivery among women who had a birth in the last three years from Uttar Pradesh, India ( $n=5427$, weighted)

\begin{tabular}{|c|c|c|}
\hline Characteristics & $\begin{array}{c}\text { Institutional } \\
\text { delivery \% }\end{array}$ & $\begin{array}{c}\text { Significance } \\
\text { (F-Statistic } p \text {-value) }\end{array}$ \\
\hline All women & 68.9 & \\
\hline \multicolumn{3}{|l|}{ Presence of elder sister-in-law } \\
\hline No & 68.5 & 0.046 \\
\hline Yes & 78.2 & \\
\hline \multicolumn{3}{|l|}{$\begin{array}{l}\text { Household type and presence of } \\
\text { mother-in-law }\end{array}$} \\
\hline $\begin{array}{l}\text { Lives in husband's natal home } \\
\text { with mother-in-law }\end{array}$ & 77.0 & 0.000 \\
\hline $\begin{array}{l}\text { Lives in husband's natal home } \\
\text { only }\end{array}$ & 61.8 & \\
\hline Lives with mother-in-law only & 74.2 & \\
\hline $\begin{array}{l}\text { Not natal home and no } \\
\text { mother-in-law }\end{array}$ & 65.6 & \\
\hline \multicolumn{3}{|l|}{ Slum sample: } \\
\hline $\begin{array}{l}\text { Household type and presence of } \\
\text { mother-in-law }\end{array}$ & & 0.005 \\
\hline $\begin{array}{l}\text { Lives in husband's natal home } \\
\text { with mother-in-law }\end{array}$ & 64.1 & \\
\hline $\begin{array}{l}\text { Lives in husband's natal home } \\
\text { only }\end{array}$ & 56.3 & \\
\hline Lives with mother-in-law only & 50.8 & \\
\hline $\begin{array}{l}\text { Not natal home and no } \\
\text { mother-in-law }\end{array}$ & 55.4 & \\
\hline \multicolumn{3}{|l|}{ Non-slum sample: } \\
\hline $\begin{array}{l}\text { Household type and presence of } \\
\text { mother-in-law }\end{array}$ & & 0.000 \\
\hline $\begin{array}{l}\text { Lives in husband's natal home } \\
\text { with mother-in-law }\end{array}$ & 80.3 & \\
\hline $\begin{array}{l}\text { Lives in husband's natal home } \\
\text { only }\end{array}$ & 63.5 & \\
\hline Lives with mother-in-law only & 77.1 & \\
\hline $\begin{array}{l}\text { Not natal home and no } \\
\text { mother-in-law }\end{array}$ & 67.6 & \\
\hline
\end{tabular}

demonstrates significant effects for living with an elder sister-in-law on modern family planning use. In particular, women living with an elder sister-in-law are significantly less likely to use modern family planning than women not living with an elder sister-in-law. In addition, controlling for the demographic factors, compared to women who neither live in the husband's natal home nor live with the mother-in-law, women who live only with the mother-in-law or women who live in the husband's natal home only are more likely to use modern family planning (OR: 1.29; 95\% CI: 1.04, 1.58 and OR: 1.14; 95\% CI: 1.05, 1.24, respectively). These results suggest that the bivariate patterns essentially still emerge after controlling for age and other demographic factors.
No difference in modern family planning use is found between women who live in the husband's natal home and with the mother-in-law and women living neither in the husband's natal home nor with the mother-in-law. In models not shown, when the reference group is living in the husband's natal home and with the mother-in-law, we find that both groups of just one scenario (either the husband's natal home or the mother-in-law) were associated with greater probability of use with $\mathrm{p}$-values of just over $0.05(\mathrm{p}=0.058$ and $\mathrm{p}=0.061$, respectively). All other variables in the model perform as expected given the findings in the previous literature on factors associated with modern family planning use in this setting [16].

Table 5 presents the results for the household type and composition variables stratified by slum and nonslum sample. In both the slum and non-slum sample, the effect of the elder sister-in-law remains the same. In the slum sample, we find that living in the husband's natal home remains positive and significant as shown in Table 4. The effect of the mother-in-law only category is positive but does not attain significance probably due to a small number of women in this category. For the nonslum sample, the findings for modern family planning use are the same as the full sample.

Model 2 in Table 4 provides the results of household composition and type on institutional delivery controlling for key demographic factors including parity. The multivariable model demonstrates that compared to women who live neither with the mother-in-law nor in the husband's natal home, women living only in the husband's natal home are significantly more likely to have an institutional delivery for their last birth (OR: 1.19; $95 \%$ CI: $(1.02,1.38))$. None of the other household type/ composition variables, including living with an elder sister-in-law, is associated with institutional delivery. The remaining demographic factors perform as expected; more educated women, lower parity births, and non-slum residents are more likely to have an institutional delivery than all others. Table 5 presents the results stratified by slum and non-slum sample. In the slum sample, the results are the same as the full model. As shown in Table 3, in the non-slum sample, women living both in the husband's natal home and with the mother in law are more likely to have an institutional delivery than women living neither in the husband's natal home nor with the mother-in-law. No significant difference is found comparing the two other classifications to the neither category in the non-slum category.

\section{Discussion}

This study found that two-thirds of women live in their husband's natal home and about half of these women also live with their mother-in-law. About a third of the 
Table 4 Multivariable logistic regression odds ratios ( $95 \%$ confidence intervals) of use of modern contraception among currently married, fecund, non-pregnant women (Model 1) and for institutional delivery for women who had a birth in the last three years (Model 2), Uttar Pradesh, India

\begin{tabular}{|c|c|c|}
\hline Covariate & Model 1 modern use & Model 2 institutional delivery \\
\hline \multicolumn{3}{|l|}{ Age (Excluded: Under 25) } \\
\hline $25-29$ & $2.37^{* * *}(2.12,2.66)$ & $1.47^{* * *}(1.24,1.73)$ \\
\hline $30-34$ & $3.64^{* * *}(3.24,4.08)$ & $1.68^{* * *}(1.36,2.09)$ \\
\hline $35+$ & $3.89^{* * *}(3.48,4.33)$ & $1.54^{* *}(1.17,2.03)$ \\
\hline \multicolumn{3}{|l|}{ Education (Excluded: No education) } \\
\hline $1-7$ years & $1.42^{* * *}(1.27,1.59)$ & $1.87^{* * *}(1.58,2.22)$ \\
\hline $8-11$ years & $1.49^{* * *}(1.35,1.64)$ & $2.53^{* * *}(2.15,2.99)$ \\
\hline $12+$ years & $1.51^{* * *}(1.37,1.67)$ & $6.89^{* * *}(5.48,8.67)$ \\
\hline \multicolumn{3}{|l|}{ Wealth (Excluded: Richest) } \\
\hline Poorest & $0.89^{*}(0.80,0.99)$ & $0.84+(0.70,1.01)$ \\
\hline Poor & $0.93(0.84,1.04)$ & $1.07(0.87,1.32)$ \\
\hline Medium & $1.01(0.90,1.13)$ & $1.06(0.86,1.32)$ \\
\hline Rich & $0.93(0.83,1.04)$ & $0.88(0.72,1.08)$ \\
\hline \multicolumn{3}{|l|}{ Type of residence (Excluded: Non-slum) } \\
\hline Slum & $0.96(0.88,1.04)$ & $0.66^{* * *}(0.57,0.77)$ \\
\hline \multicolumn{3}{|l|}{ City (Excluded: Agra) } \\
\hline Aligarh & $0.70^{* * *}(0.61,0.80)$ & $0.58^{* * *}(0.45,0.75)$ \\
\hline Allahabad & $0.86^{*}(0.75,1.00)$ & $0.71^{*}(0.54,0.94)$ \\
\hline Gorakhpur & $0.87+(0.78,1.01)$ & $0.44^{* * *}(0.34,0.58)$ \\
\hline Moradabad & $1.13+(1.00,1.28)$ & $0.44^{* * *}(0.34,0.57)$ \\
\hline Varanasi & $1.11(0.96,1.28)$ & $0.75^{*}(0.58,0.97)$ \\
\hline \multicolumn{3}{|l|}{ Caste (Excluded: scheduled caste or tribe) } \\
\hline Other backward caste & $0.93(0.84,1.03)$ & $1.12(0.94,1.35)$ \\
\hline None & $0.96(0.86,1.07)$ & $1.57^{* * *}(1.28,1.92)$ \\
\hline \multicolumn{3}{|l|}{ Religion (Excluded: Muslim/Other) } \\
\hline Hindi & $1.06(0.88,1.27)$ & $1.06(0.74,1.54)$ \\
\hline \multicolumn{3}{|l|}{ Parity (Excluded: 4+) } \\
\hline 1 & - & $3.23^{* * *}(2.56,4.08)$ \\
\hline 2 & - & $1.85^{* * *}(1.51,2.28)$ \\
\hline 3 & - & $1.51^{* * *}(1.24,1.82)$ \\
\hline \multicolumn{3}{|c|}{ Presence of elder sister-in-law (Excluded: Not living with sister-in-law) } \\
\hline Sister-in-Law in Residence & $0.71^{* * *}(0.58,0.87)$ & $0.94(0.65,1.36)$ \\
\hline \multicolumn{3}{|c|}{ Household type and presence of mother-in-law (Excluded: Lives with neither) } \\
\hline Lives with mother-in-law only & $1.29^{*}(1.04,1.58)$ & $0.98(0.67,1.45)$ \\
\hline Lives in husband's natal home only & $1.14^{* *}(1.05,1.24)$ & $1.19^{*}(1.02,1.38)$ \\
\hline Living in husband's natal and with mother-in-law & $1.05(0.90,1.15)$ & $1.14(0.97,1.34)$ \\
\hline
\end{tabular}

Parity was not included in the family planning use model. $+p \leq 0.10 ;{ }^{*} p \leq 0.05 ; * * p \leq 0.01 ; * * p \leq 0.001$.

sample lives neither with the mother-in-law nor in the husband's natal home. The study findings illustrate that among women living with the mother-in-law and in the husband's natal home and women living with neither the mother-in-law nor in the husband's natal home the prevalence of modern family planning use is the lowest
(49 and 53 percent, respectively). In addition, living with an elder sister-in-law was also found to be associated with lower overall family planning use. Women living with just the mother-in-law or women living only in the husband's natal home (without the mother-in-law) are more likely to use modern FP than women living neither 
Table 5 Multivariable logistic regression odds ratios ( $95 \%$ confidence intervals) of use of modern contraception among currently married, fecund, non-pregnant women (Model 1) and for institutional delivery for women who had a birth in the last three years (Model 2), Uttar Pradesh, India

\begin{tabular}{|c|c|c|c|c|}
\hline Covariate & $\begin{array}{l}\text { Model } 1 a-\text { slum } \\
\text { Modern use } \\
(n=7360)\end{array}$ & $\begin{array}{c}\text { Model } 1 b-\text { non-slum } \\
\text { Modern use } \\
(n=7161)\end{array}$ & $\begin{array}{l}\text { Model } 2 a-\text { slum } \\
\text { Institutional delivery } \\
\quad(n=3016)\end{array}$ & $\begin{array}{l}\text { Model } 2 \mathrm{~b}-\text { non-slum } \\
\text { Institutional delivery } \\
\qquad(\mathrm{n}=\mathbf{2 5 9 5 )}\end{array}$ \\
\hline \multicolumn{5}{|l|}{$\begin{array}{l}\text { Presence of elder sister-in-law } \\
\text { (Excluded: Not living with sister-in-law) }\end{array}$} \\
\hline Sister-in-law in residence & $0.66^{* *}(0.49,0.88)$ & $0.77+(0.58,1.02)$ & $0.84(0.52,1.37)$ & $1.12(0.62,2.03)$ \\
\hline \multicolumn{5}{|l|}{$\begin{array}{l}\text { Household type and presence of mother-in-law } \\
\text { (Excluded: Lives with neither) }\end{array}$} \\
\hline Lives with mother-in-law only & $1.23(0.87,1.76)$ & $1.32 *(1.02,1.72)$ & $0.79(0.47,1.34)$ & $1.35(0.74,2.49)$ \\
\hline Lives in husband's natal home only & $1.17^{*}(1.03,1.32)$ & $1.11+(0.99,1.24)$ & $1.20+(0.99,1.46)$ & $1.13(0.89,1.42)$ \\
\hline Living in husband's natal and with mother-in-law & $1.06(0.93,1.21)$ & $1.03(0.91,1.17)$ & $1.03(0.83,1.27)$ & $1.29^{*}(1.01,1.66)$ \\
\hline
\end{tabular}

Parity was not included in the family planning use model. $+p \leq 0.10 ;{ }^{*} \mathrm{p} \leq 0.05 ;{ }^{* *} \mathrm{p} \leq 0.01$. models unweighted.

in the husband's natal home nor with the mother-in-law and women living in the combined scenario. For institutional delivery, we find less association between household type and composition. Women living in the husband's natal home (no mother-in-law) were significantly more likely to have an institutional delivery than women living neither with the mother-in-law nor in the husband's natal home. In addition, in the non-slum sample, women living in the husband's natal home and with the mother-in-law were the most likely to have an institutional delivery.

Our findings that show less family planning use and less institutional delivery among women living neither in the husband's natal home nor with the mother-in-law contrast previous studies from South Asia. In particular, recent studies demonstrated that women living in multigenerational households are less likely to be using modern FP $[7,28]$ and to have an institutional delivery [23] as compared to women living in nuclear households (with just the husband, wife, and their unmarried children present). Furthermore, men living in multi-generational households tend to want larger family sizes than those in nuclear households [25] and some of their reproductive decisions may be influenced by the larger family network $[7,28]$. Other studies from South Asia have demonstrated the importance of mothers-in-law in influencing sexual and reproductive health behaviors, including the timing of childbearing, use of FP, and the role of the daughter-in-law in the household $[22,24,33,34]$. Notably, the influence of the mother-in-law may differ by whether the couple lives with the mother-in-law in the same household or not. For example, family planning use has been found to be lower when the mother-in-law lives with the couple as compared to when the couple lives separately from the mother-in-law [7].

A possible explanation for our counter-intuitive findings may be based on the focus on urban areas. Multi- generational households in South Asia are common in both rural and urban areas and may be even more important for the urban poor who have fewer resources to set up an independent household at the time of union formation. Notably, new urban residents may find themselves in settings that do not include other family members if they are the first to migrate to their urban area. These residents may be influenced by their former (possibly rural) roots in decision-making about reproductive health behaviors. These attitudes and desires are likely associated with less overall FP use and non-institutional delivery. Consistent with our hypothesis was that women who live both in the husband's natal home and with the mother-in-law were less likely to use family planning than women in only one of these scenarios. These results are likely indicative of a cumulative effect of living within both scenarios for women in these urban settings. Our results also indicate that while only a small percentage of women live with an elder sister-in-law (i.e., wife of the husband's older brother), these women demonstrated significantly lower overall modern family planning use. Whether this is indicative of greater social pressures to have children in multi-family and intergenerational households or is indicative of younger wives in multi-generational households needing to have a son to attain status, or to a specific influence of the elder sisterin-law is not possible to ascertain with the current data. Future studies of multi-generational households in urban settings would need to interview all of the women in the household and compare their fertility and FP behaviors to better understand the role of this family composition category.

Household type was also found to be associated with institutional delivery for one particular scenario: controlling for all other factors, women living only in their husband's natal home were significantly more likely to have an institutional delivery than women living neither in 
the husband's natal home nor with the mother-in-law. Furthermore, among women living in non-slum areas, those who lived both with the mother-in-law and in the husband's natal home were the most likely to have an institutional delivery. These findings are interesting in light of earlier studies. In particular, Saikia and Singh [23], using nationally representative data from India, show that women living in joint households (with in-laws) are less likely to have an institutional delivery than women living in nuclear households (just the husband and wife with their children). Further, studies from rural areas have indicated that mothers-in-law play a key role after delivery of a (first) birth [24]. Our study focuses on major urban areas and hence may be different than national or rural samples given that our sample has high access to institutional delivery and more than two-thirds of women have any education; these factors may influence women's reproductive health (particularly delivery) decision-making. Consistent with this, Hou and Ma [32], using data from Pakistan, find that first time pregnancies are more likely to be delivered in a health institution indicating the ability of first time mothers to overcome barriers to institutional delivery that are experienced by women having higher order pregnancies. Future studies, possibly using qualitative data collection, are needed to examine in greater depth urban women's roles, household composition and type and how these are associated with their place of delivery and other reproductive health decision-making. One other factor that is likely also related to choice of an institutional delivery is the Government of India's Janani Suraksha Yojana (JSY or safe motherhood) Scheme launched in 2005. JSY is a national conditional cash transfer program that offers incentives to women of low socioeconomic status to have an institutional delivery [27]. With this program in place, choice of institutional delivery may be influenced by desire for extra cash rather than influenced by cultural norms to deliver at home that traditionally come from relatives and extended family. It is notable, however, that we found that women from slums were significantly less likely to have an institutional delivery no matter the household composition/type. This is indicative of possible gaps in the JSY program in urban settings of Uttar Pradesh.

This study is not without limitations. First and foremost, the data for this study are cross-sectional and thus it is not possible to be assured of the direction of causality. For example, the mother-in-law present in the household could be a consequence of a recent birth; if the mother-in-law was not present prior to delivery, she is less likely to influence the place of delivery. Second, the determination of household composition was based on the household roster which indicates the relationship between all individuals listed in the roster and the head of that household. In some cases, elder women in the household who could be influential were present but could neither be categorized as an elder sister-in-law nor a mother-in-law; these women's influences are not factored into the models. Notably, the question on place of residence (husband's natal home or not) was selfreported by women; it is expected that this is a more reliable indicator than the created indicator of presence of the mother-in-law or presence of an elder sister-in-law.

\section{Conclusion}

To conclude, where women live and who they live with matter for FP use but only the former seems to matter for institutional delivery in the six major urban areas of Uttar Pradesh included in this analysis. Given the important role of the sister-in-law and mother-in-law and that women living in poorer settings are less likely to use modern FP, outreach programs to slum/poor areas may be crucial for improving the social context for FP. Outreach programs can target women of reproductive age but should also include activities with other influential women and family members in the household and community. These programs should promote the importance of family planning use for spacing and limiting births. These same outreach programs targeting poor/ slum sites could also promote institutional delivery and the JSY program given that we found that poorer/slum women were less likely to deliver in an institution. Finally, it is important to develop programs for those women who are the least attached to their urban setting (i.e., not in the husband's natal home nor with the mother-in-law). These women were the least likely to use modern FP and had lower levels of institutional delivery compared to their counterparts living in the husband's natal home and with the mother-in-law. These women potentially are the least trusting of outreach workers/visitors. Programs for these women may need to start by offering basic health care for the women and their children to help gain their trust and engagement of the husband/wife for future outreach for FP and delivery services. These types of targeted programs that address the social context within which women live are likely to have the biggest impacts on the Millennium Development Goals of reducing maternal mortality and achieving universal access to FP and reproductive health services for women and families in Uttar Pradesh, India.

\section{Competing interests}

The authors declare that they have no competing interests.

\section{Authors' contributions}

ISS conceived of the study, developed the initial models, and wrote the first draft of the text; PML undertook in-depth modeling, wrote parts of an earlier draft and reviewed all drafts of the paper; RV reviewed all drafts of the paper, providing local context for the findings. AMB undertook the complex matching exercise to identify the relationships between all household members and reviewed final drafts of the paper. All authors read and approved the final manuscript. 


\section{Acknowledgements}

Funding for this work comes from the Bill \& Melinda Gates Foundation. This research was also supported by grant, 5 R24 HD050924, Carolina Population Center, awarded to the Carolina Population Center at The University of North Carolina at Chapel Hill by the Eunice Kennedy Shriver National Institute of Child Health and Human Development. The contents of this paper are solely the responsibility of the authors and do not necessarily represent the official views of the funders. The authors would like to thank Lisa Calhoun for her review and insights into an earlier draft of this paper.

\section{Author details}

'Department of Maternal and Child Health, Gillings School of Global Public Health, The University of North Carolina at Chapel Hill, Chapel Hill, NC, USA. ${ }^{2}$ Carolina Population Center, University of North Carolina at Chapel Hill,

Chapel Hill, USA. International Center for Research on Women, Delhi, India.

Received: 17 April 2014 Accepted: 26 December 2014

Published: 12 January 2015

\section{References}

1. Cates W. Family planning: the essential link to achieving all eight millennium development goals. Contraception. 2010;81:460-1.

2. Ezeh AC, Kodzi I, Emina J. Reaching the urban poor with family planning services. Stud Fam Plan. 2010;41:109-16.

3. Montagu D, Yamey G, Visconti A, Hardin A, Yoong J. Where do poor women in developing countries give birth? a multi-country analysis of demographic and health survey data. PLoS ONE. 2011;6(2):e17155.

4. Montgomery MR. Urban poverty and health in developing countries. Popul Bull. 2009;64(2).

5. Ortayli N, Malarcher S. Equity analysis: Identifying who benefits from family planning programs. Stud Fam Plan. 2010;41(2):101-8.

6. Simkhada B, Porter MA, van Teijlingen ER. The role of mothers-in-law in antenatal care decision-making in Nepal: a qualitative study. BMC Pregnancy Childbirth. 2010;10:34.

7. Kadir MM, Fikree FF, Khan A, Sajan F. Do mothers-in-law matter? Family dynamics and fertility decision-making in urban squatter settlements of Karachi, Pakistan. J Biosoc Sci. 2003;35:545-58. doi:10.1017/S0021932003005984

8. Mumtaz Z, Salway SM. Gender, pregnancy and the uptake of antenatal care services in Pakistan. Sociol Health IIIn. 2007:29(1):1-26.

9. Stephenson R, Baschieri A, Clements S, Hennink M, Madise N. Contextual influences on modern contraceptive use in sub-Saharan Africa. Am J Public Health. 2007;97(7):1233-40.

10. Cleland JG, Ndugwa RP, Zulu EM. Family planning in sub-Saharan Africa: progress or stagnation? Bull World Health Organ. 2011;89:137-43. doi:10.2471/BLT.10.077925.

11. Mathe JK, Kasonia KK, Maliro AK. Barriers to adoption of family planning among women in Eastern Democratic Republic of Congo. Afr J Reprod Health. 2011;15(1):69-77.

12. White D, Dynes M, Rubardt M, Sissoko K, Stephenson R. The influence of intrafamilial power on maternal health care in Mali: perspectives of women, men and mothers-in-law. Int Perspect Sex Reprod Health. 2013;39(2):58-68.

13. Gage AJ. Barriers to the utilization of maternal health care in rural Mali. Soc Sci Med. 65(8):1666-82.

14. Stephenson R, Baschieri A, Clements S, Hennink M, Madise N. Contextual influences on the use of health facilities for childbirth in Africa. Am J Public Health. 2006;96(1):84-93.

15. Paul VK, Sachdev HS, Mavalankar D, Ramachandran P, Sankar MJ, Bhandari $\mathrm{N}$, et al. Reproductive health, and child health and nutrition in India: meeting the challenge. Lancet. 2011;377:332-49.

16. Speizer IS, Nanda P, Achyut P, Pillai G, Guilkey DK. Family planning use among urban poor women from six cities of Uttar Pradesh, India. J Urban Health. 2012;89:639-58

17. Bloom SS, Wypij D, DasGupta M. Dimensions of women's autonomy and the influence on maternal health care utilization in a North Indian city. Demography. 2001;38:67-78.

18. Cleland J, Bernstein S, Ezeh A, Faundes A, Glasier A, Innis J. Family planning: the unfinished agenda. Lancet. 2006;368:1810-27.

19. Hubacher D, Mavranezouli I, McGinn E. Unintended pregnancy in sub-Saharan Africa: magnitude of the problem and potential role of contraceptive implants to alleviate it. Contraception. 2008;78:73-8.
20. Kesterton AJ, Cleland J, Sloggett A, Ronsmans C. Institutional delivery in rural India: the relative importance of accessibility and economic status. BMC Pregnancy Childbirth. 2010;10:30. 10.1186/1471-2393-10-30.

21. Thind A, Mohani A, Banerjee K, Hagigi F. Where to deliver? Analysis of choice of delivery location from a national survey in India. BMC Public Health. 2008;8:29. 10.1186/1471-2458-8-29.

22. Char A, Saavala M, Kulmala T. Influence of mothers-in-law on young couples' family planning decisions in India. Reprod Health Matters. 2010;18(35):154-62.

23. Saikia N, Singh A. Does type of household affect maternal health? Evidence from India. J Biosoc Sci. 2009;41:329-53.

24. Das Gupta M. Life course perspectives on women's autonomy and health outcomes. Health Transit Rev Suppl. 1996;6:213-31.

25. Avan Bl, Akhund $\mathrm{S}$. Role of family type in the idealization of a larger number of children by husbands in Pakistan. J Biosoc Sci. 2005;38(2):203-20.

26. International Institute for Population Sciences (IIPS) and Macro International. National Family Health Survey (NFHS-3), 2005-06: India: Volume I. Mumbai: IIPS; 2007.

27. Lim SS, Dandona L, Hoisington JA, James SL, Hogan MC, Gakidou E. India's Janani Suraksha Yojana, a conditional cash transfer programme to increase births in health facilities: an impact evaluation. Lancet. 2010;375:2009-23.

28. McCleary-Sills J, McGonagle A, Malhotra A. Women's Demand for Reproductive Control: Understanding and Addressing Gender Barriers. Washington DC: International Center for Research on Women (ICRW); 2012.

29. Fikree FF, Khan A, Kadir MM, Sajan F, Rahbar MH. What influences contraceptive use among young women in urban squatter settlements of Karachi, Pakistan? Int Fam Plan Perspect. 2001;27(3):130-6.

30. Stephenson R, Hennink M. Barriers to Family Planning Service use Among Urban Poor in Pakistan, Opportunities and Choices Working Paper No. 2. 2004.

31. Prakash R, Kumar A. Urban poverty and utilization of maternal and child health care services in India. J Biosoc Sci. 2013;45:433449.

32. Hou X, Ma N. The effect of women's decision-making power on maternal health services uptake: Evidence from Pakistan. Health Policy Plan. 2013;28(2):176-84.

33. Bates LM, Maselko J, Schuler SR. Women's education and the timing of marriage and childbearing in the next generation: evidence from rural Bangladesh. Stud Fam Plan. 2007;38(2):101-12.

34. Mumtaz Z, Salway S. Understanding gendered influences on women's reproductive health in Pakistan: moving beyond the autonomy paradigm. Soc Sci Med. 2009;68:1349-56.

doi:10.1186/1742-4755-12-4

Cite this article as: Speizer et al.: Descriptive study of the role of household type and household composition on women's reproductive health outcomes in urban Uttar Pradesh, India. Reproductive Health 2015 12:4

\section{Submit your next manuscript to BioMed Central and take full advantage of:}

- Convenient online submission

- Thorough peer review

- No space constraints or color figure charges

- Immediate publication on acceptance

- Inclusion in PubMed, CAS, Scopus and Google Scholar

- Research which is freely available for redistribution 